\title{
Resiliência e Velhice: um estudo comparativo entre idosos de diferentes níveis socioeconômicos
}

Resilience and Old Age: a comparative study among elderly people of different socioeconomic levels

Resiliencia y Vejez: un estudio entre personas mayores de diferentes niveles socioeconómicos

Ludgleydson Fernandes de Araújo Rayfran José Sousa Silva José Victor de Oliveira Santos

RESUMO: A presente investigação teve como objetivo principal estudar e comparar os níveis de resiliência entre idosos de diferentes classes sociais (baixa renda e alta renda). Participaram 20 idosos, com idades que variam de 61 a 84 anos $(M=67,75 \mathrm{DP}=6,17)$. A partir da entrevista semiestruturada, utilizou-se a análise de conteúdo de Bardin. Os idosos de ambos os grupos relataram dificuldades decorrentes do período da velhice e estão munidos de ideias e recursos para superar os empecilhos que a vida apresenta.

Palavras-chave: Resiliência; Velhice; Classes sociais.

ABSTRACT; The present study had as main objective to study and compare the levels of resilience between elderly people of different social classes (low income and high income). Twenty elderly individuals, ranging in age from 61 to 84 years $(M=67,75 S D=6.17)$ participated. From the semi-structured interview, we used Bardin's content analysis. The elderly in both groups reported difficulties arising from the old age and are equipped with ideas and resources to overcome the obstacles that life presents.

Keywords: Resilience; Aging; Social classes. 
RESUMEN: Esta investigación tuvo como objetivo estudiar y comparar los niveles de resiliencia entre las personas mayores de diferentes clases sociales (de bajos y altos ingresos). Participaron 20 personas mayores, de edades entre 61-84 años $(M=67, D T=$ 6.17 75). De la entrevista semiestructurada se utilizó el análisis de contenido de Bardin. Ancianos de ambos grupos informaron de las dificultades derivadas de período de la vejez y están provistos de ideas y recursos para superar los obstáculos que la vida presenta.

Palabras clave: Resiliencia; Vejez; Clases Sociales.

\section{Introdução}

O presente trabalho traz um estudo sobre a resiliência na velhice. Esta pesquisa corresponde a uma comparação nos modos de vida e capacidades para enfrentar as adversidades em idosos de diferentes classes ou níveis sociais (baixa renda e alta renda). $\mathrm{O}$ maior acesso aos serviços sócio-sanitários, e o consequente aumento na expectativa de vida, tem ocasionado o aumento significativo da população idosa no Brasil e no mundo (Araújo, Amaral, \& Sá, 2014). Dessa forma, algumas políticas públicas para este contingente populacional foram elaboradas e implementadas na realidade brasileira; um exemplo disso foi a Política Nacional do Idoso (Lei n. ${ }^{\circ} 8.842$ de 04/01/1994), que teve como objetivo dar garantias sociais às pessoas a partir dos 60 anos e mais. Outra conquista social importante foi a promulgação do Estatuto do Idoso (Lei n. ${ }^{\circ} 10.741$ de 01/10/2003), que ampliou os direitos e deveres das pessoas idosas.

Estima-se que sejam incorporados à população brasileira cerca de 650 mil novos idosos a cada ano (Araújo, Amaral, \& Sá, 2014). Esses autores ainda mencionam que, nas últimas décadas, a população mundial vem apresentando uma inversão demográfica, devido à tendência crescente na expectativa média de vida; assim, a longevidade está se tornando um fenômeno que tem gerado muitas discussões e especulações sociais, econômicas, biológicas e emocionais.

O termo senescência ou envelhecimento se remete a um processo evolutivo, em que, com o passar dos anos ou aumento da idade, os indivíduos passarão por algumas transformações, apresentando disfunções, devido a essas modificações corporais, comuns a todo o sujeito que envelhece (Ciosak, et al., 2011). 
Envelhecimento é um processo gradual que vai se desenvolvendo no decorrer da vida, apresentando mudanças tanto biológicas, como fisiológicas, psicossociais e funcionais, que se dão de forma permanente entre o sujeito e a sua relação com o ambiente. Envelhecimento ativo e saudável é um processo de bem-estar mental, físico e social, com participação em atividades sociais, culturais, econômicas, espirituais, entre outros fatores, como também contar com medidas de proteção, seguridade e atenção, que tem por objetivo ampliar a esperança e qualidade de vida saudável (OEA, 2015).

Um construto psicossocial relevante para compreender os mecanismos de superação das adversidades na velhice é a resiliência. A resiliência é definida como a resistência adquirida às adversidades ou riscos psicossociais. Tal fenômeno requer a atenção para uma série de questões psicológicas e não somente se pautar a um fato positivo do indivíduo, mas, sim, analisar cuidadosamente outros fatores determinantes (Rutter, 1999). Para a psicologia, a resiliência está ligada aos recursos pessoais, que levam a comportamentos adaptativos, como a autoestima, a autoeficácia e a capacidade para resolver problemas. Estes atuam como protetores diante das adversidades (Rutter, 1987).

Atualmente no contexto mundial, torna-se impossível o ser humano não passar por algum tipo de adversidade durante o decorrer da sua vida. Essas adversidades variam bastante e podem ir desde uma briga conjugal, por exemplo, ao final de um relacionamento, a morte de algum ente querido, ou até mesmo a perda de bens materiais em um desastre natural. Nesse sentido, determinadas situações para alguns podem ser bem traumáticas, chegando a ponto de impossibilitar que a vida dê seu seguimento. Para outros, enfrentar as dificuldades faz parte de um processo que é mais elaborado, no sentido de que o sujeito, mesmo passando por momentos de dificuldade, passe a conseguir encará-los e com isso permite que sua vida decorra normalmente (Angst, 2009).

Frederic Flach, um dos primeiros autores a discutir sobre o conceito resiliência, traz uma nova explicação sobre este construto, sendo uma interpretação mais voltada para as competências individuais dos sujeitos diante das adversidades. Fez em 1966 a afirmação de que, para que uma pessoa possa ser resiliente, ela deverá ter competência individual de poder fazer o reconhecimento da dor pela qual está passando; com isso perceber seu sentido e manter-se tolerante a ela durante algum período de tempo, até que essa pessoa possa conquistar a capacidade de buscar modos para resolver determinado conflito, de forma útil, que possa lhe trazer benefícios individuais. 
Esse mesmo autor ainda complementa suas reflexões, afirmando que o termo não está sendo referido somente aos aspectos psicológicos, mas também aos aspectos fisiológicos e físicos (Flach, 1991).

O construto resiliência não é um traço, melhor dizendo, não advém exclusivamente de traços que o indivíduo apresenta, mas depende também das mudanças que acontecem nos espaços das vivências de cada um, ou seja, no local em que as pessoas trocam experiências. Pode ser compreendida por meio de respostas fisiológicas ou de modificações que ocorrem no corpo, que responde a estímulos externos. Isso vai depender das experiências individuais de cada um (Rutter, 2007).

É um processo que envolve o êxito, quando se refere ao desenvolvimento dos indivíduos. O ser humano resiliente passa a progredir, ganhar, e evoluir, tornando-se apto à adaptação diante das circunstâncias que lhes são oferecidas, mesmo quando está exposto a situações adversas, quando ocorre a interação genética e ambiental (Ungar, 2011).

Muitos pesquisadores concordam quanto à visão de que o processo de enfrentamento a situações adversas esteja ligado a questões biológicas de cada indivíduo em constante influência com o meio social, onde ocorrem as trocas de relações.

Esta pesquisa se torna relevante à medida que promove o esclarecimento sobre algumas questões, como é o caso da influência que a renda exerce sobre a saúde ou o bemestar das pessoas, mais especificamente o público idoso, e a relação que estabelece com a resiliência.

Para tanto, como norteador da pesquisa, quando se trata da questão renda mensal, foram utilizados os dados da Pesquisa Nacional por Amostra de Domicílios (PNAD) — um estudo acerca da renda familiar (Singer, 2015).

Este estudo visa a compreender como os idosos de diferentes níveis socioeconômicos encaram algumas implicações, adversidades ou problemas sociais emergentes.

E por que estudar esses grupos de idosos? A questão-alvo é realizar um estudo investigativo de análise e compreensão de aspectos referentes ao construto resiliência em idosos de diferentes níveis socioeconômicos (alto e baixo). 


\section{Método}

\section{Lócus da Investigação}

A presente investigação foi desenvolvida na cidade de Parnaíba, Piauí, Brasil, em ambientes públicos, havendo aplicação de instrumentos necessários ao processo investigativo do presente artigo, para obtenção de dados necessários à realização da análise e publicação de resultados, respeitando-se o critério visto na literatura acerca da delimitação das classes sociais proposta pela PNAD (Singer, 2015).

\section{Tipo de Investigação}

Trata-se de uma pesquisa quali-quantitativa ex post facto, utilizando-se de dados transversais.

\section{Participantes}

Participaram idosos de dois grupos de diferentes níveis socioeconômicos, cada um composto por 10 pessoas, de ambos os sexos, utilizando-se como indicador de delimitação a idade igual ou superior a 60 anos, idade em que as pessoas são consideradas como idosas, segundo o Instituto Brasileiro de Geografia e Estatística (IBGE, 2014).

Os participantes desta pesquisa relacionada à classe considerada baixa possuem uma média de idade compreendida entre 64 a 84 anos; e da classe alta, idades que vão de 61 a 71 anos. No total, a idade dos participantes variou entre 61 a $84 \operatorname{anos}(\mathrm{M}=67,75$ e o $\mathrm{DP}=6,17)$.

A seguir, os dados na Tabela 1: 
Tabela 01- Características sociodemográficas dos idosos de ambas os níveis socioeconômicos

\begin{tabular}{|c|c|c|c|}
\hline Baixo & $(\%)$ & $\begin{array}{l}\text { Nível Socioeconômico } \\
\text { Alto }\end{array}$ & $(\%)$ \\
\hline \multicolumn{2}{|l|}{ Sexo } & \multicolumn{2}{|l|}{ Sexo } \\
\hline Mulheres & $60 \%$ & Mulheres & $40 \%$ \\
\hline Homens & $40 \%$ & Homens & $60 \%$ \\
\hline \multicolumn{2}{|l|}{ Escolaridade } & \multicolumn{2}{|l|}{ Escolaridade } \\
\hline Sem Estudos & $10 \%$ & Sem Estudos & $0 \%$ \\
\hline Ensino Fundamental & $60 \%$ & $\begin{array}{l}\text { Ensino } \\
\text { Fundamental }\end{array}$ & $0 \%$ \\
\hline Ensino Médio & $30 \%$ & Ensino Médio & $10 \%$ \\
\hline Ensino Superior & $0 \%$ & Ensino Superior & $90 \%$ \\
\hline Outro & $0 \%$ & Outro & $0 \%$ \\
\hline \multicolumn{2}{|l|}{ Ocupação } & \multicolumn{2}{|l|}{ Ocupação } \\
\hline Dona (o) de Casa & $30 \%$ & Dona (o) de Casa & $0 \%$ \\
\hline Servidor Público & $20 \%$ & Servidor Público & $90 \%$ \\
\hline Outro & $50 \%$ & Outro & $10 \%$ \\
\hline \multicolumn{2}{|l|}{ Renda Mensal } & \multicolumn{2}{|l|}{ Renda Mensal } \\
\hline 1 salário mínimo & $70 \%$ & 1 salário mínimo & $0 \%$ \\
\hline 2 salários mínimos & $30 \%$ & 2 salários mínimos & $0 \%$ \\
\hline 3 a 4 salários mínimos & $0 \%$ & 3 a 4 salários mínimos & $0 \%$ \\
\hline 5 ou mais salários mínimos & $0 \%$ & 5 ou mais salários mínimos & $100 \%$ \\
\hline
\end{tabular}

\section{Instrumentos}

Questionários sociodemográficos, para a obtenção de informações sobre o sexo, idade, estado civil, escolaridade, etnia, renda, situação de moradia e saúde, para delinear um perfil dos participantes. 
Entrevista semiestruturada, com a finalidade de compreender a percepção dos idosos sobre a autopercepção e enfrentamento das adversidades.

\section{Procedimentos}

O projeto da presente pesquisa foi enviado para avaliação do Comitê de Ética em Pesquisa (CEP) da Universidade Federal do Piauí para ser apreciada, sendo aprovada com o Certificado de Apresentação para Apreciação Ética (CAAE): 52615115115.3.0000.5669. Após a aprovação do CEP, os dois grupos de idosos foram informados sobre o início da coleta de dados.

Para os idosos que aceitaram participar da pesquisa, foi solicitado que assinassem o termo de consentimento livre e esclarecido, TCLE. De forma individual, cada participante recebeu as informações do pesquisador sobre o termo, a pesquisa e as implicações de sua participação, juntamente com o acompanhamento ofertado até o final da pesquisa. $\mathrm{O}$ termo contém as informações referentes à pesquisa junto aos devidos esclarecimentos sobre a participação voluntária. O participante de forma livre decidiu se queria ou não participar do trabalho e até mesmo sobre a possível eventualidade de uma desistência, sem que houvesse prejuízos.

Foi realizada uma entrevista semiestruturada. Nesta, o informante pôde discorrer sobre suas experiências a partir do foco que é proposto pelo pesquisador; nesta o informante dá respostas espontâneas e livres. As questões elaboradas para a realização da entrevista levaram em consideração o embasamento teórico da investigação junto às informações recolhidas referentes ao fenômeno social (Triviños, 1987). Levando em consideração estes pontos, foram criadas as seguintes perguntas: 1) Quais os principais problemas enfrentados no seu dia a dia?; 2) Como você age frente aos problemas da vida?; e 3) Como você percebe sua velhice? A aplicação dos instrumentos teve um tempo médio de aproximadamente 30 minutos para cada sujeito. Não foi observada nenhuma recusa por parte dos idosos para participar da presente investigação. 


\section{Análise dos dados}

Os dados da entrevista semiestruturada foram realizados por meio de uma análise de conteúdo. A análise de conteúdo enquanto método se torna um somatório de técnicas de exploração das comunicações, que utilizam procedimentos sistemáticos e objetivos, para a descrição do conteúdo das mensagens que são passadas através dos relatos adquiridos (Bardin, 2016). Devido à redundância nas respostas durante a obtenção dos dados, optou-se pela finalização da amostra por saturação teórica (Fontanella, et al., 2011).

\section{Resultados e Discussão}

A análise dos dados, após leituras dos conteúdos apresentados, resultou em três categorias, sendo elas: problemas enfrentados na velhice, formas de enfrentamento das adversidades da velhice e concepções acerca da velhice; e oito subcategorias. Com relação aos problemas enfrentados na velhice, apresentam-se as seguintes subcategorias: desgaste psicológico, desgaste fisiológico e desgaste social. Quanto às formas de enfrentamento: atividades socioculturais e os recursos individuais. Quanto às concepções: vitalidade, senescência e adversidades (Tabela 2):

Tabela 02 - Problemas Enfrentados na Velhice

\begin{tabular}{l|c|c|c|c}
\hline \multirow{2}{*}{ Subcategorias } & \multicolumn{2}{|c|}{$\begin{array}{c}\text { Nível } \\
\text { Socioeconômico Baixo }\end{array}$} & \multicolumn{2}{c}{$\begin{array}{c}\text { Nível } \\
\text { Socioconômico Alto }\end{array}$} \\
\cline { 2 - 5 } & F & \% & F & $\%$ \\
\hline Desgaste Psicológico & 19 & 53 & 11 & 30 \\
\hline Desgaste fisiológico & 08 & 22 & 01 & 03 \\
\hline Desgaste Social & 09 & 25 & 24 & 67 \\
\hline Total & 36 & $100 \%$ & 36 & 100 \\
\hline
\end{tabular}


Os idosos de ambos os níveis socioeconômicos apresentam dificuldades decorrentes do período da velhice, em maior proporção à questão relacionada ao desgaste psicológico, $53 \%$, no caso dos idosos (nível socioeconômico baixo) (ver Tabela 2).

Nos idosos do nível socioeconômico alto, o desgaste social vem como sendo o de maior proporção, apresentando $67 \%$.

Nas respostas citadas pelos idosos (de nível socioeconômico baixo), que se relacionam ao desgaste psicológico, se apresentam o sofrimento causado pelos problemas de saúde, a saudade dos familiares, o abandono, a rejeição, os problemas de relacionamento interpessoal, as preocupações com as demandas que a vida apresenta, a incapacidade para a realização de atividades cotidianas e a solidão. Em menor frequência, como é o caso do desgaste social e fisiológico, eles trazem questões como: lutas diárias, dificuldade na relação com os familiares, hipertensão, problemas intestinais e de visão.

Com relação aos dados apresentados que fazem referência ao público composto pelo nível socioeconômico baixo, relacionados aos problemas enfrentados na velhice, os idosos trazem o desgaste psicológico como sendo frequente, diante de todos os problemas que eles enfrentam, podendo-se citar a alteração no estilo de vida, o que acaba por contribuir para que ocorram dificuldades nas suas relações interpessoais. Nesse sentido, pode-se supor que um fator está atrelado a outro, colocando-se que, se determinado idoso enfrenta problemas psicológicos, estes acabam por alterar negativamente sua vida social. Os fatores fisiológicos comprometidos surgem e podem derivar tanto por questões próprias do processo de senescência, como também pelo fator psicológico, dando lugar às doenças psicossomáticas.

Um idoso do sexo masculino, de 80 anos, quando questionado sobre quais os principais problemas enfrentados no seu dia a dia, afirmou: "Quero fazer as coisas e não posso. Estar doente, enfrentar as doenças e não passar bem. Sou sozinho e longe da família. Tenho saudade dos filhos. Tenho pensamentos negativos por estar só. Falta um filho homem para me auxiliar".

Nesse sentido através da fala, fica claro o desgaste no fator psicológico, como o sofrimento por conta de algumas impossibilidades que surgem no âmbito social, como a falta de apoio social, o que acaba por gerar solidão e a doença que se faz presente, ocorrendo com isso a união de três fatores que afetam a vida do idoso. 
No que tange às respostas fornecidas pelos idosos (de nível socioeconômico alto), e que se relacionam com o desgaste social, aparecem questões relacionadas como: enfrentar o trânsito caótico na cidade, a falta de respeito e educação entre as pessoas, a marginalidade que há na sociedade, as dificuldades em acessar atividades remuneradas, as dificuldades em acompanhar as novas tecnologias, o desgaste social por conta de relacionamentos interpessoais, a falta de segurança e as muitas tarefas do dia a dia, que deixam débitos familiares. Em menor proporção, estão as subcategorias desgaste fisiológico e psicológico, quando ocorreram questões como: solidão, aborrecimentos, estresse, insônia e o cansaço corporal.

Dos dois fatores que mais se apresentaram, pontua-se a fala de um idoso de 69 anos que, ao ser questionado sobre quais os principais problemas enfrentados no seu dia a dia, relata: "Tenho problemas em enfrentar o trânsito caótico da cidade, as pessoas que não respeitam os direitos dos outros, a marginalidade crescente pela falta de oportunidade e a má-educação dos nossos semelhantes". Nesse sentido, ficam evidentes, através do relato desse idoso, as dificuldades enfrentadas por ele que estão relacionadas a fatores sociais e, atreladas a isso, as dificuldades em lidar com questões associadas, o que leva a um comprometimento dos fatores psicológicos da maioria dos sujeitos.

A pesquisa sobre a resiliência identifica fatores que incluem a vulnerabilidade, referindo-se àqueles que intensificam os riscos e os fatores de proteção, e que designa aqueles que se modificam em uma direção considerada positiva acerca dos efeitos do risco (Luthar, \& Brown, 2007). Em função disso, para que ocorra a pesquisa em resiliência, é necessário que ocorra a presença dos fatores negativos e, com isso, ao investigar determinados contextos da vida do sujeito, verificar os mecanismos de proteção que ele próprio desenvolve ao longo do tempo.

Muitas vezes, o envelhecer está associado com declínios diversos, tanto fisiológicos como funcionais, e estes podem contribuir para a fragilidade e incapacidade (Seguin, \& Nelson, 2003). Esta afirmativa corrobora a ocorrência da subcategoria desgaste fisiológico, no que se refere aos problemas adquiridos devido à chegada da velhice, em maior proporção nos idosos da classe baixa que, quando comparados aos idosos de classe alta, apresentam uma diferença relativa a $19 \%$.

Consequentemente ao desgaste fisiológico, o desgaste social se faz presente, como pôde ser visto nos idosos de ambas as classes, enfatizando-se sua maior prevalência nos idosos (de nível socioeconômico alto). 
Por tudo isso, torna-se necessário que ocorra a resiliência como uma reserva individual para os idosos lidarem com suas dificuldades. Dessa forma, o indivíduo que possui resiliência poderá adotar resultados satisfatórios na busca pela obtenção de competências individuais para lidar com suas dificuldades pessoais, sem que evite os fatores negativos, mas podendo enfrentar suas adversidades (Cowan, P.A., Cowan, C.P., \& Schulz, 1996).

Tabela 03 - Formas de Enfrentamento das Adversidades da Velhice

\begin{tabular}{l|c|c|c|c}
\hline \multirow{2}{*}{ Subcategorias } & \multicolumn{2}{|c|}{$\begin{array}{c}\text { Nível } \\
\text { Socioeconômico Baixo }\end{array}$} & \multicolumn{2}{c}{$\begin{array}{c}\text { Nível } \\
\text { Socioeconômico Alto }\end{array}$} \\
\cline { 2 - 5 } & F & \% & F & \% \\
\hline $\begin{array}{l}\text { Atividades } \\
\text { Socioculturais }\end{array}$ & 33 & 53 & 16 & 63 \\
\hline Recursos Individuais & 29 & 47 & 27 & 100 \\
\hline Total & 62 & 100 & 43 & \\
\hline
\end{tabular}

No que se refere a enfrentar as adversidades da velhice, foram identificadas as seguintes subcategorias: atividades socioculturais e recursos individuais (ver Tabela 3). Os idosos (de nível socioeconômico baixo) apresentaram 53\% quanto às questões relacionadas a atividades socioculturais, nível maior que os da classe alta, que apresentaram 37\%. Quanto aos recursos individuais para enfrentamento das dificuldades presentes por conta do processo de senescência na velhice, os idosos (de nível socioeconômico baixo) apresentaram um nível menor, sendo de $47 \%$ e no nível socioeconômico alto com $63 \%$.

Nas atividades socioculturais, os idosos pertencentes ao nível socioeconômico baixo citam como exemplo: participação em grupos de idosos, realização da dança, ir a grupos de convivência, realização de atividades físicas, atividades artesanais, produção de poesias, conversar com as pessoas próximas, estar no ambiente de trabalho, jogar futebol e sair com os amigos como uma forma de descontração. Em relação à subcategoria recursos individuais, surgem aspectos como: tranquilidade, distração, ouvir música a força e a garra, a fé e o otimismo, a utilização dos meios de comunicação para enfrentar a saudade de pessoas queridas, buscando ter pensamentos positivos com relação às diferentes situações. 
Em contrapartida, os idosos que pertencem ao nível socioeconômico alto, nas atividades socioculturais apresentam: prática de dirigir, buscar por atividades que possuem profissionais qualificados e que possam atender as suas demandas individuais, ir à igreja, assistir filmes e ouvir música. Nos recursos individuais, eles se utilizam de algumas alternativas, entre elas: a paciência, o amor para com os outros, buscando ter boa convivência com as pessoas que o cercam, buscando superar através de recursos individuais as dificuldades que vão surgindo, com coragem, serenidade e tranquilidade para encarar a vida.

Os idosos (de nível socioeconômico baixo) utilizam-se da participação em atividades sócio culturais, possuindo também recursos individuais para enfrentarem as suas dificuldades. Participar de atividades que proporcionem a relação social com os demais foi um fator frequente; neste sentido corrobora o que foi visto sobre o fator resiliência e as maneiras de enfrentar as dificuldades, a partir da participação em diferentes contextos, que proporcionam a troca, através das relações interpessoais, havendo, assim, a vontade individual do sujeito e o deslocar-se ao encontro de algo que lhe proporcione prazer de vida.

Essas questões ficam claras na fala de uma idosa de 65 anos que, ao ser questionada sobre como ela age relativamente aos problemas comuns da vida, ela afirmou que: "Procuro conversar, procuro os meus amigos, conto histórias, adivinhações, escuto música, assisto TV, filmes, faço atividades físicas na praça, participo de grupo de idosos pois eles existem dança e prática do alongamento".

Em contrapartida quanto ao nível socioeconômico, um idoso da classe alta, que tem 61 anos quando questionado sobre como ele age diante dos problemas da vida revelou:

"Primeiro reconhecer que ele existe e, assim, absorver e trabalhar para depois superar. Assim, utilizo a música como forma lúdica de recomposição. Gosto de experimentar os recursos disponíveis por ser algo concreto. Gosto de yoga, leitura. A yoga ajuda na respiração, respiração é vida, através dela controlo o sono e o cansaço, para dar bom encaminhamento à vida. Acredito no espiritual. A yoga contribui não só para o físico, mas para o lado espiritual, ou seja, ela acaba contribuindo para as questões subjetivas do ser humano como um todo (atualmente estou um pouco afastado por conta do tempo)." 
A resiliência é a capacidade que o indivíduo possui de resolver suas demandas cotidianas, de forma positiva, apesar das dificuldades, sendo que essas capacidades são atributos do próprio indivíduo, do seu ambiente familiar, cultural e social (Noronha, Cardoso, Moraes, \& Centa, 2009).

A resiliência se desenvolve caso o idoso se sinta cuidado, se o meio em que este vive consegue enxergar sua importância, se o próprio idoso é cuidadoso consigo mesmo, se ele respeita os seus limites e, acima de tudo, reconhece-se como tendo um potencial. A resiliência não é uma coisa inata ao ser humano, mas é uma construção que se dá continuamente e que possui relação com vários fatores, dentre eles, os biológicos, sociais e culturais (Secunho, 2012).

Nas atividades socioculturais dos idosos, de ambos os níveis socioeconômicos, as classes ocorrem por meio de uma troca. Não é somente o idoso que participa, mas todas as pessoas que fazem parte do seu convívio na realização das tarefas que ocorrem de forma direta ou indireta. É com as reservas ou aptidões do sujeito dignas de seus recursos individuais, somadas às atividades que se dão no meio social, que ocorrem trocas de relações, que a resiliência poderá ser construída e vivenciada.

Tabela 04 - Concepções Acerca da Velhice

\begin{tabular}{|c|c|c|c|c|}
\hline \multirow[t]{2}{*}{ Subcategorias } & \multicolumn{2}{|c|}{$\begin{array}{c}\text { Nível } \\
\text { Socioeconômico Baixo }\end{array}$} & \multicolumn{2}{|c|}{$\begin{array}{c}\text { Nível } \\
\text { Socioeconômico Alto }\end{array}$} \\
\hline & $\mathbf{F}$ & $\%$ & $\mathbf{F}$ & $\%$ \\
\hline Vitalidade & 18 & 53 & 28 & 57 \\
\hline Senescência & 06 & 18 & 08 & 16 \\
\hline Adversidades & 10 & 29 & 13 & 27 \\
\hline Total & 34 & 100 & 49 & 100 \\
\hline
\end{tabular}

Como pode ser verificado na Tabela 4 , esta pesquisa demonstra, através dos dados apreendidos, as concepções acerca da velhice. Foram retiradas três subcategorias, sendo elas: vitalidade, senescência e adversidades. 
Tanto os idosos da classe baixa, como os da classe alta, apresentaram alto índice de vitalidade, havendo pouca diferença entre ambos, sendo 53\% de nível socioeconômico baixo, seguidos por $57 \%$ de nível alto. Relativamente ao processo de envelhecimento e enfrentamento das adversidades, não houve diferenças significativas.

Nas questões relacionadas à vitalidade, os idosos (de nível socioeconômico baixo) apresentaram questões como: serem autônomos para realização das suas atividades cotidianas, disposição para a prática das suas tarefas diárias, havendo comparações com o passado na época da jovialidade, percebem o passar dos anos de forma positiva e que somam boas expectativas, a garra e a vontade de enfrentar as dificuldades está sempre presente. Por outro lado, quanto aos idosos (de nível socioeconômico alto), os exemplos de vitalidade incluem: estarem em atividades plenas, serem ativos (fazerem sempre exercícios diários), participar de atividades como a yoga e a meditação, o que contribui para o bem-estar espiritual.

Na subcategoria senescência, os idosos (de nível socioeconômico alto) relataram questões como: problemas de saúde que surgem devido às transformações decorrentes do envelhecimento, mudanças na aparência como o ressecamento da pele e o aparecimento de cabelos brancos. Já os idosos (de nível socioeconômico alto) trazem quesitos como: um processo natural do ser humano e a redução da força física.

Quanto às adversidades, os idosos (nível socioeconômico baixo) abarcam os seguintes pontos: desânimo, desconforto, falta de estrutura para encarar os problemas, o sofrimento e a redução dos anos de vida. Em contrapartida, os idosos (nível socioeconômico alto), exibem aspectos como: encarar o desgaste do corpo que se tona mais frágil, enfrentamento das doenças, a impossibilidade para realizar ações do cotidiano, a aceitação das suas condições e com a visão da velhice de uma forma natural.

Relacionado aos dados expostos sobre o perfil do idoso que possui menor nível social, sobre as categorias e subcategorias definidas, coloca-se que os mesmos possuem uma grande vitalidade, o que é demonstrada através dos relatos dos mesmos, diante do estilo de vida que adotam, ainda com as adversidades que se apresentam. Eles demonstram gostar de estarem ativos e praticarem atividades que lhes tragam prazer de viver e bem-estar. O espírito de jovialidade se faz presente, havendo a vitalidade para executar diferentes exercícios do dia a dia, incluindo as atividades físicas e mentais. 
Ambos os grupos colocam a senescência e as adversidades em segundo plano, apresentando porcentagem menor quando comparada à vitalidade. Este fator reforça a ideia de que, mesmo perante as adversidades que surgem no período da velhice, os idosos adquirem recursos próprios como a obtenção do espírito jovial para encarar a vida. Abaixo são enunciados dois relatos dos idosos de ambas os níveis socioeconômicos.

Uma idosa de nível socioeconômico baixo de 65 anos, quando questionada sobre a forma como ela percebe a sua velhice, menciona que: "Me sinto bem apesar das dificuldades; vou enfrentando as batalhas; tenho garra para enfrentar os problemas, não deixo me abater; me sinto feliz". Sobre este relato, fica perceptível que esta idosa possui vitalidade para lidar com sua rotina diária, apesar das dificuldades pelas quais ela passa. As adversidades existem, juntamente com a ideia da senescência, mas a vitalidade prevalece mesmo diante desses fatores, o que é positivo para que os idosos possam encarar as dificuldades que a vida apresenta.

Outra fala relevante emerge de uma idosa de 62 anos (nível socioeconômico alto), que, ao ser questionada sobre como percebe sua velhice, relata:

“A minha aparência me mostra que estou ficando idosa, mas não me considero uma idosa porque estou em plena atividade. Gosto de usar as tecnologias no tempo livre para falar com meus filhos e netos. Me percebo ativa e não como uma pessoa impossibilitada. Faço atividades variadas, igual na minha juventude. Sé a aparência acusa a idade, pois tenho pique como sempre tive na juventude. Tudo é costume. Já sou acostumada a trabalhar desde muito cedo, sendo incentivada pelos pais. Sempre cuido da família e trabalho com tudo fazendo várias atividades como costurar, cozinhar, faço trabalhos manuais, lido com muitas pessoas, pinto a casa, bordo, faço tricô, corto cabelo, lavo o carro, limpo a casa."

A resiliência é um elemento mediador e protetor. Através dela se dá o afrontamento do estresse, dos problemas de depressão, da ansiedade, dos traumas que o indivíduo adquire por conta dos eventos negativos pelos quais vivencia, entre outros. Atua também prevenindo que ocorram enfermidades físicas. As pessoas podem ser resilientes, mesmo vivendo em ambientes de vulnerabilidade psicossocial (Araújo, Teva, \& Bermúdez, 2015). 
Através dos fatores apresentados, são abordados aspectos inerentes aos idosos de ambas as classes sociais, no que diz respeito às suas estratégias de enfrentamento, como se dá a superação dos problemas diante das adversidades, bem como é a visão da velhice, na concepção dos próprios idosos participantes desta pesquisa.

Para os idosos de ambas as classes sociais, superar é a principal medida a ser adotada diante das estratégias de enfrentamento. Superar é vencer e obter coragem, tendo-se a capacidade para seguir a vida, muito embora existam dificuldades. Na velhice, a tranquilidade (nível socioeconômico baixo) e a maturidade (nível socioeconômico alto) se fazem presentes, somando aspectos positivos que se sobressaem aos negativos.

Ambos os grupos apresentam problemas decorrentes do período da velhice, como é o caso do desgaste psicológico e fisiológico, que, na classe baixa, ocorrem com maior frequência. Os idosos (nível socioeconômico alto) apresentam mais fatores que estão relacionados ao desgaste social. As atividades socioculturais se dão em maior nível nos idosos de classe baixa. Em contrapartida, os idosos de maior nível apresentaram mais recursos individuais do que os de menor nível para enfrentarem as adversidades presentes na velhice.

A partir do conjunto de dados desta pesquisa, não foram observadas diferenças significativas entre os grupos investigados. Pode-se destacar em primeiro lugar que os idosos de ambos os grupos construíram uma autopercepção positiva acerca do seu processo de envelhecimento independentemente do pertencimento à classe socioeconômica, bem como do acesso aos serviços sociosanitários diferenciados para cada grupo de idosos. Em segundo lugar, é válido mencionar que o enfrentamento das adversidades (resiliência) na velhice se fez presente em ambos os grupos, como recurso para lidar com as perdas inerentes ao envelhecimento humano.

\section{Considerações Finais}

A presente pesquisa buscou identificar a resiliência na velhice, de forma comparativa entre idosos de diferentes níveis socioeconômicos (alto e baixo). Nesse sentido, os dados apreendidos entre os idosos de ambos os grupos investigados apresentaram aspectos positivos diante dos estímulos negativos de vida que se apresentam dentro do contexto sociocultural de cada grupo. 
Levando-se em consideração o contexto psicossocial dos idosos (ambos os níveis socioeconômicos) e as singularidades de cada um, que refletem em um contexto que é amplo, e que retrata diferentes formas de expressão, pode-se concluir que tanto os idosos que possuem um nível socioeconômico menos favorecido, como aqueles mais favorecidos financeiramente apresentam aspectos inerentes ao construto resiliência. Os aspectos positivos se sobressaem aos negativos.

Vale ressaltar um aspecto importante nesta investigação: os idosos pertencentes aos níveis socioeconômicos baixos, em sua maioria, praticam atividades mais voltadas aos dispositivos de saúde pública; já os da classe alta não participam desse mesmo contexto, havendo uma diferença significante quanto aos recursos utilizados por ambos os grupos. Contudo, tanto um como o outro buscam, dentro do meio social em que estão inseridos, meios de enfrentarem as suas adversidades.

O presente artigo possui algumas limitações, tendo-se em vista que os dados são restritos a um pequeno número de participantes dentro de contextos socioculturais específicos. Por essa questão, de forma parcimoniosa, os resultados não podem ser generalizados para outros contextos socioculturais e grupos populacionais. No entanto, espera-se que tais dados possam subsidiar novas investigações com maior abrangência populacional, bem como possa embasar futuras intervenções psicogerontológicas que tenham como escopo atenuar os estereótipos negativos e preconceitos com relação à velhice, e aumentar as concepções positivas e as formas de enfrentamentos das adversidades inerentes ao processo de envelhecimento humano.

\section{Referências}

Angst, R. (2009). Psicologia e resiliência: uma revisão de literatura. Psicologia Argumento, 27(58), 253-260. Recuperado em 01 julho, 2016, de: file:///C:/Users/Dados/Downloads/pa-3252\%20(2).pdf.

Araújo, L. F, Amaral, E. B., \& Sá, E. C. N. (2014). Análise semântica da violência na velhice sob a perspectiva de estudantes de ensino médio. São Paulo, SP: PUC-SP: Revista Kairós Gerontologia, 17(2), 105-120. Recuperado em 01 julho, 2016, de: https://revistas.pucsp.br/index.php/kairos/article/viewFile/21334/15624.

Araújo, L. F., Teva, I., \& Bermúdez, M. D. L. P. (2015). Resiliencia en adultos: una revisión teórica. Terapia Psicológica,33(3), 257-276. Recuperado em 01 julho, 2016, de: http://www.scielo.cl/pdf/terpsicol/v33n3/art09.pdf. 
Bardin, L. (2016). Análise de conteúdo. Lisboa, Portugal: Edições 70.

Ciosak, S. I., Braz, E., Costa, M. F. B. N. A., Nakano, N. G. R., Rodrigues, J., Alencar, R. A., \& Rocha, A. C. A. L. da (2011). Senescência e senilidade: novo paradigma na atenção básica de saúde. Revista da Escola de Enfermagem, 45(2), 1763-1768. Recuperado em 01 julho, 2016, de: http://dx.doi.org/10.1590/S0080-62342011000800022.

Cowan, P. A., Cowan, C. P., \& Schulz, M. S. (1996). Thinking about Risk and Resilience in Families. In: Hetherington, E. M., \& Blechman, E. (Eds.). Stress, Coping, and Resiliency in Children and Families, Advances in Family Research, 1-38. Mahwah, NJ: Lawrence Erlbaum Associates.

Estatuto do Idoso. (2003). Lei $n .^{o} 10.741$ de 01/10/2003. Secretaria Nacional dos Direitos Humanos. Brasília, DF: Ministério da Justiça.

Fontanella, B. J. B., Luchesi, B. M., Saidel, M. G. B., Ricas, J., Turato, E. R., \& Melo, D. G. (2011). Amostragem em pesquisas qualitativas: proposta de procedimentos para constatar saturação teórica. Rio de Janeiro, RJ: Cadernos de Saúde Pública, 27(2), 389-394. Recuperado em 01 julho, 2016, de: http://www.scielo.br/pdf/csp/v27n2/20.pdf.

IBGE. (2014). Instituto Brasileiro de Geografia e Estatística. Síntese de indicadores sociais uma análise das condições da população brasileira. Estudos e Pesquisas Informações Demográfica e Socioeconômica. Rio de Janeiro, RJ.

Luthar, S. S., \& Brown, P. J. (2007). Maximizing resilience through diverse levels of inquiry: Prevailing paradigms, possibilities, and priorities for the future. Development and Psychopathology, 19(3), 931-55. Recuperado em 01 julho, 2016, de: https://www.ncbi.nlm.nih.gov/pubmed/17705909.

Noronha, M. G. R. da C. e S., Cardoso, P. S., Moraes, T. N. P., \& Centa, M. de L. (2009). Resiliência: nova perspectiva na Promoção da Saúde da Família? Ciência \& Saúde Coletiva, 14(2), 497-506. Recuperado em 01 julho, 2016, de: http://dx.doi.org/10.1590/S1413-81232009000200018.

OEA (2015). Organização dos Estados Americanos. Convención Interamericana sobre la Protección de los Derechos Humanos de las Personas Mayores. Washington, D.C. (15 al 16 de junio).

Política Nacional do Idoso. (1998). Lei $n .^{o} 8.842$ de 04/01/1994. Secretaria Nacional dos Direitos Humanos. Brasília, DF: Ministério da Justiça.

Rutter, M. (1987). Psychosocial resilience and protective mechanisms. American journal of orthopsychiatry, 57(3), 316-331. Recuperado em 01 julho, 2016, de: doi: 10.1111/j.19390025.1987.tb03541.x.

Rutter, M. (1999). Resilience concepts and findings: implications for family therapy. Journal of family therapy, 21(2), 119-144. Recuperado em 01 julho, 2016, de: doi: 10.1111/14676427.00108 .

Rutter, M. (2007). Resilience, competence, and coping. Child Abuse \& Neglect. J. Chiabu. 31(3), 205-209. Recuperado em 01 julho, 2016, de: https://doi.org/10.1016/j.chiabu.2007.02.001.

Secunho, C. F. (2012). Resiliência: a arte de enfrentar a adversidade no ciclo da vida. Brasília, DF: Thesaurus. 
Seguin, R. \& Nelson, M. E. (2003) The benefits of strenght training for older adults. American Journal of Preventive Medicine, 25(3), 141-149. Recuperado em 01 julho, 2016, de: https://www.ncbi.nlm.nih.gov/pubmed/14552938.

Singer, A. (2015). Quatro notas sobre as classes sociais nos dez anos do lulismo. São Paulo, SP: Psicol. USP, 26(1), s.p. Recuperado em 01 julho, 2016, de: ttp://dx.doi.org/10.1590/0103-6564D20140012.

Triviños, A. N. S. (1987). Introdução à pesquisa em ciências sociais: a pesquisa qualitativa em educação. São Paulo, SP: Atlas.

Ungar, M. (2011). The social ecology of resilience: addressing contextual and cultural ambiguity of a nascent construct. American Journal of Orthopsychiatry, 81(1), 01-17. Recuperado em 01 julho, 2016, de: doi: 10.1111/j.1939-0025.2010.01067.x.

Recebido em 18/01/2017

Aceito em 31/03/2017

Ludgleydson Fernandes de Araújo - Doutor em Psicologia, Universidade de Granada, Espanha, com período-sanduíche na Università di Bologna, Itália. Professor Adjunto do Programa de Pós-Graduação (Stricto sensu) em Psicologia, Universidade Federal do Piauí, UFPI, Campus Ministro Reis Velloso. Parnaíba, PI, Brasil.

E-mail: ludgleydson@yahoo.com.br

Rayfran José Sousa Silva - Psicólogo, Universidade Federal do Piauí, UFPI, Campus Ministro Reis Velloso. Parnaíba, PI, Brasil.

E-mail: ray_files@hotmail.com

José Victor de Oliveira Santos - Bolsista de Iniciação Científica PIBIC/CNPq. Graduando em Psicologia, Universidade Federal do Piauí, UFPI, Campus Ministro Reis Velloso.

Parnaíba, PI, Brasil.

E-mail: victorolintos@hotmail.com 